\title{
Análise energética de sistemas solares térmicos para diferentes demandas de água em uma residência unifamiliar
}

Energy analysis of solar thermal systems for different demands of hot water in a single family dwelling

\section{Leandra Altoé \\ Delly Oliveira Filho J oyce Correna Carlo}

\section{Resumo}

Leandra Altoé Departamento de Engenharia Agrícola, Centro de Ciências Agrárias Universidade Federal de Viçosa Av. Peter Henry Rolfs, s/n, sala 324 Campus Universitário Vicosa - MG - Brasil CEP 36570-000

Tel.: (31) 3899-1897

E-mail: leandraaltoe@gmail.com

Delly Oliveira Filho Departamento de Engenharia Agrícola, Centro de Ciências Agrárias

Universidade Federal de Viçosa E-mail: dellyoliveira@gmail.com

J oyce Correna Carlo Departamento de Engenharia Agrícola, Centro de Ciências Agrárias Universidade Federal de Viçosa Tel.: (31) 3899-1982 E-mail: correnacarlo@gmail.com

Recebido em 01/02/12

Aceito em 03/09/12

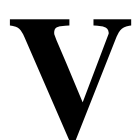

ários países têm utilizado a energia solar com a finalidade de reduzir a dependência de combustíveis fósseis e as emissões de gases de efeito estufa. Os edifícios comerciais, públicos e residenciais são responsáveis por $47,6 \%$ do consumo de energia elétrica no Brasil. O chuveiro elétrico é o equipamento com maior participação de consumo em residências brasileiras, seguido da geladeira e do ar-condicionado. Objetivou-se com este trabalho analisar a eficiência energética de um sistema solar térmico com apoio elétrico para atender diferentes demandas de água quente em uma residência unifamiliar, comparativamente ao uso de chuveiro elétrico. No dimensionamento do sistema solar foram considerados parâmetros do Programa Brasileiro de Etiquetagem de edifícios e da norma técnica NBR 15569/2008. O aquecedor solar foi simulado pelo programa EnergyPlus nas condições climáticas de Viçosa, Minas Gerais. Entre outras variáveis, foram avaliadas a fração solar do sistema, a energia transferida ao coletor solar, a energia armazenada no reservatório térmico e o consumo de energia elétrica pelas duas opções de aquecimento. Foi verificado que a substituição do chuveiro elétrico pelo aquecedor solar com backup elétrico provocou uma redução média de $70 \%$ no consumo de energia elétrica destinado a aquecimento de água e $36 \%$ no consumo total de energia elétrica da residência.

Palavras-chave: Energia solar. Aquecimento de água. Edificações.

\section{Abstract}

Several countries have been using solar energy in order to reduce dependence on fossil fuels and to cut greenhouse gas emissions. Commercial, public and residential buildings are responsible for $47.6 \%$ of the electricity consumption in Brazil. Electric water heaters are the biggest energy consumers in Brazilian dwellings, followed by refrigerators and air-conditioners. The objective of this study is to analyze the energy efficiency of a solar water heating system with electric backup to meet the different hot water demands of a single-family dwelling, comparing it with electric water heaters. The parameters of the Brazilian Labeling Program for buildings and those of the technical standard NBR 15569/2008 were considered in the dimensioning of the the solar heating system. The solar heating system was simulated using the EnergyPlus software in the climatic conditions of Viçosa, Minas Gerais. The variables analyzed included the solar fraction, the energy transferred to the solar panels, the energy stored in the storage tank and the electricity consumption of the two water heating options. The results indicated that the replacement of the electric shower by the solar heater with electric backup led to an average reduction of $70 \%$ in electricity consumption for water heating and 36\% of the dwelling's total electricity consumption.

Keywords: Solar energy. Water heating. Buildings. 


\section{Introdução}

Entre todas as fontes de energias disponíveis, a energia solar é a mais abundante e pode ser explorada nas formas direta e indireta. Se $0,1 \%$ da radiação solar que atinge a superfície terrestre fosse convertida em energia elétrica, a $10 \%$ de eficiência, seria gerada uma quantidade equivalente a quatro vezes a capacidade de produção mundial instalada. No entanto, $80 \%$ da energia utilizada atualmente no mundo possui origem em fontes não renováveis (THIRUGNANASAMBANDAM; INIYAN; GOIC, 2010).

De acordo com expectativas do setor energético, a demanda mundial de combustíveis fósseis deverá ultrapassar a produção anual provavelmente dentro das próximas duas décadas (THIRUGNANASAMBANDAM; INIYAN; GOIC, 2010). Além disso, a necessidade de reduzir as emissões de gases de efeito estufa, com a finalidade de alcançar metas definidas em tratados internacionais, como o Protocolo de Quioto, têm impulsionado muitos países a utilizar fontes renováveis, incluindo energia solar térmica e fotovoltaica (KALOGIROU, 2009).

Os edifícios são responsáveis por $20 \%$ a $40 \%$ do consumo de energia em países desenvolvidos, superando a demanda dos setores da indústria e de transportes na União Europeia. Os sistemas de aquecimento, ventilação e ar condicionado respondem por quase metade da energia consumida nos edifícios e por cerca de $10 \%$ a $20 \%$ do consumo energético em países desenvolvidos (LOMBARD; ORTIZ; POUT, 2008).

Segundo dados do Balanço Energético Nacional referentes a 2009, os edifícios comerciais, públicos e residenciais são responsáveis por $47,6 \%$ do consumo de energia elétrica no Brasil, com destaque para o setor residencial, cuja participação é de 23,9\% (BRASIL, 2010a). Os equipamentos com maior parcela de consumo de energia elétrica em residências brasileiras são o chuveiro elétrico, a geladeira e o ar-condicionado (ELETROBRAS, 2007).

Uma alternativa para reduzir o consumo energético no setor residencial é a substituição do chuveiro elétrico por sistemas solares térmicos. Pesquisas realizadas em diversos países comprovam a viabilidade técnico-econômica do uso de aquecedores solares de água, comparativamente às opções de aquecimento elétrico e a gás (CRAWFORD; TRELOAR, 2004; OLIVEIRA et al., 2008; KALOGIROU, 2009).

Vários países têm incentivado o uso de energias renováveis em edificações por meio de promulgações de leis, normas e programas de certificação energética (CASALS, 2006). No Brasil, diversas leis sobre uso de energia solar térmica em edifícios estão aprovadas ou em tramitação em vários estados brasileiros, entre eles São Paulo, Rio de Janeiro, Minas Gerais, Goiás, Mato Grosso, Pernambuco, Paraná e Santa Catarina (DEPARTAMENTO..., 2012). Na cidade de São Paulo, por exemplo, a Lei $n^{\circ} 14.459$ determina a utilização compulsória de aquecedores solares de água em edifícios residenciais com quatro banheiros ou mais e a instalação obrigatória de estrutura para receber o sistema solar térmico em edifícios residenciais com três banheiros ou menos, construídos a partir de 3 de julho de 2008 (SÃO PAULO, 2007).

$\mathrm{O}$ uso de energia solar em edifícios também tem sido estimulado no país pelo Programa Brasileiro de Etiquetagem (PBE), realizado pelo Procel em parceria com o Inmetro. Atualmente, a certificação de eficiência energética de edificações é voluntária no país e destinada a edifícios residenciais, comerciais, públicos e de serviços, mas a tendência é que em alguns anos torne-se obrigatória (FOSSATI; LAMBERTS, 2010).

O Brasil recebe níveis médios de radiação solar superiores aos observados na maioria dos países europeus e com variabilidade sazonal baixa, devido a grande parte do país estar presente na zona tropical (MARTINS; PEREIRA, 2011). Apesar disso, o número de projetos destinados ao uso de energia solar no Brasil, tanto para aproveitamento térmico quanto para a geração de energia fotovoltaica, é inexpressivo quando comparado com os existentes em alguns países europeus, como Alemanha, Espanha e França (MARTINS; PEREIRA; ABREU, 2007).

A exploração do potencial solar brasileiro pode proporcionar benefícios para diferentes setores da sociedade e menores danos ao meio ambiente, comparado ao uso de fontes energéticas convencionais. $\mathrm{O}$ aproveitamento da energia solar pode retardar a necessidade de investimentos em usinas geradoras de eletricidade, evitando impactos ambientais negativos decorrentes da instalação e operação desses empreendimentos (OLIVEIRA et al., 2008). Além disso, o maior uso de aquecedores solares de água em residências pode melhorar a gestão de cargas no horário de ponta, com consequente aumento na confiabilidade do sistema elétrico brasileiro (NASPOLINI; MILITÃO; RÜTHER, 2010).

Dessa forma, este artigo tem como objetivo analisar a eficiência energética de um sistema de 
aquecimento solar de água destinado a atender a diferentes demandas de água quente em uma residência unifamiliar, comparativamente ao uso de chuveiro elétrico.

\section{Metodologia}

Neste trabalho foi empregada uma tipologia residencial e padrões de uso de iluminação e de eletrodomésticos definidos por Tavares (2006) e Sorgato (2009). O modelo representa uma residência unifamiliar destinada a quatro moradores, com área construída de $63 \mathrm{~m}^{2}$, dois dormitórios, sala, cozinha e banheiro. Segundo Tavares (2006), esse modelo possui características que representam $58 \%$ das edificações residenciais brasileiras. O modelo habitacional descrito é apresentado na Figura 1.

Foi considerado que a residência possui demanda de água quente apenas para banho, atendida por chuveiro elétrico ou aquecedor solar com apoio elétrico (por meio de uma resistência elétrica instalada no interior do reservatório térmico). $\mathrm{O}$ aquecedor solar empregado na análise é composto de coletores solares planos e reservatório térmico, com circulação natural de água (efeito termossifão). Na Figura 2, é apresentado um esquema do aquecedor solar de água descrito.

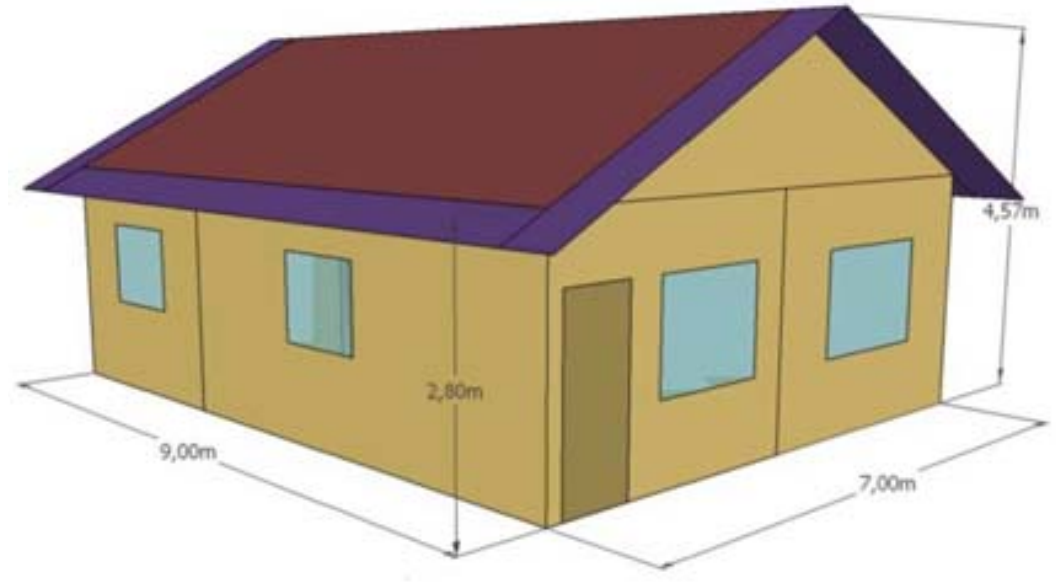

Figura 1 - Representação geométrica do modelo residencial analisado

Fonte: Sorgato (2009).

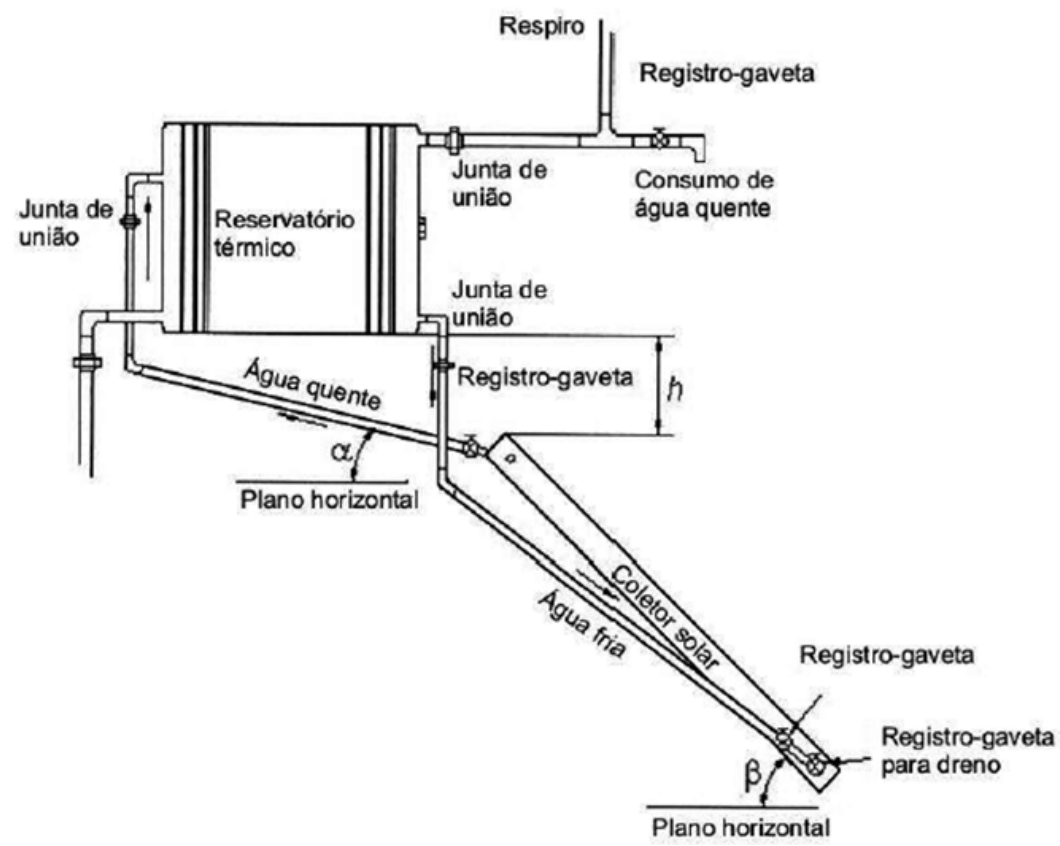

Figura 2 - Esquema de um aquecedor solar de água por termossifão

Fonte: ABNT (2008). 
A norma brasileira de referência sobre projetos de aquecimento solar de água, a NBR 15569, recomenda o uso de vazões de chuveiros de 3 a 15 $\mathrm{L} / \mathrm{min}$ no dimensionamento de sistemas solares térmicos (ABNT, 2008). Com o objetivo de avaliar diferentes vazões como um fator de qualidade para o usuário, foram considerados três níveis de conforto de banho: conforto reduzido (vazão do chuveiro de $3 \mathrm{~L} / \mathrm{min}$ ), conforto regular (vazão do chuveiro de $5 \mathrm{~L} / \mathrm{min}$ ) e conforto bom (vazão do chuveiro de $8 \mathrm{~L} / \mathrm{min}$ ).

Para cada condição de conforto de banho foram dimensionados sistemas solares de aquecimento de água com diferentes níveis de eficiência energética pela certificação brasileira de edifícios residenciais. Os parâmetros de classificação são apresentados no Regulamento Técnico da Qualidade do Nível de Eficiência Energética de Edifícios Residenciais (RTQ-R) (BRASIL, 2010b). Além disso, para cada condição de conforto de banho, foi dimensionado um aquecedor solar por meio da metodologia apresentada na NBR 15569 (ABNT, 2008). A metodologia presente na norma calcula a área de coletores solares necessária com base na demanda de água quente, radiação solar do local de instalação do sistema, eficiência dos coletores, entre outros parâmetros, para que seja atendida uma fração solar anual teórica de $70 \%$. A fração solar é dada pela razão entre a energia solar térmica gerada pelo sistema e a demanda total de energia para aquecimento de água.
$\mathrm{Na}$ certificação de eficiência energética de edifícios residenciais, o sistema de aquecimento solar de água é avaliado pela fração solar anual e por pré-requisitos específicos para cada nível de eficiência energética. Sistemas com fração solar anual igual ou superior a $70 \%$ são classificados como nível A. Para sistemas com fração solar anual inferior a $70 \%$, o nível de eficiência energética é obtido por meio da ponderação dos equivalentes números do sistema solar e do sistema de energia auxiliar pela demanda de água quente atendida por cada sistema. No caso de aquecedores com fração solar inferior a $70 \%$ e com backup elétrico, calcula-se o equivalente numérico ponderado do sistema solar/elétrico com base nos valores apresentados nas Tabelas 1 e 2, e em seguida obtém-se o nível de eficiência energética do sistema de aquecimento de água pela Tabela 3 .

Após a determinação do nível de eficiência energética pelo cálculo da fração solar anual, é necessário verificar se o sistema atende aos prérequisitos específicos para o nível de eficiência encontrado. Caso os pré-requisitos não sejam atendidos, o nível de eficiência energética final do sistema de aquecimento de água será rebaixado. Entre os pré-requisitos específicos para a obtenção do nível $\mathrm{A}$ ou $\mathrm{B}$ estão: coletores solares com Etiqueta Nacional de Conservação de Energia (Ence) A ou B pelo PBE e reservatórios térmicos com Selo Procel (BRASIL, 2010b).

Tabela 1 - Equivalente numérico para sistemas de aquecimento solar

\begin{tabular}{c|c}
\hline Fração solar anual, FS (\%) & Equivalente numérico \\
\hline FS $\geq 70$ & 5 \\
$60 \leq \mathrm{FS} \leq 69$ & 4 \\
$50 \leq \mathrm{FS} \leq 59$ & 3 \\
$\mathrm{FS}<50$ & 2 \\
\hline
\end{tabular}

Fonte: Brasil (2010b).

Tabela 2 - Equivalente numérico para sistemas de aquecimento elétrico

\begin{tabular}{c|c}
\hline Potência elétrica, $\mathbf{P}(\mathbf{W})$ & Equivalente numérico \\
\hline $\mathrm{P} \leq 4.600$ & 2 \\
$\mathrm{P}>4.600$ & 1 \\
\hline
\end{tabular}

Fonte: Brasil (2010b).

Tabela 3 - Correspondência entre equivalente numérico e nível de eficiência energética

\begin{tabular}{c|c}
\hline Nível de eficiência energética & Equivalente numérico \\
\hline A & 5 \\
B & 4 \\
C & 3 \\
D & 2 \\
E & 1 \\
\hline
\end{tabular}

Fonte: Brasil (2010b).

78 Altoé, L.; Oliveira Filho, D.; Carlo, J. C. 
As duas referências nacionais empregadas neste trabalho, NBR 15569 (ABNT, 2008) e RTQ-R (BRASIL, 2010b), calculam a eficiência energética de aquecedores solares com circulação de água forçada e natural (termossifão) pelo método CartaF (BECKMAN; KLEIN; DUFFIE, 1977). Apesar de muito difundido em vários países, inclusive no Brasil, esse método foi desenvolvido com base em aquecedores solares com circulação forçada e apresenta limitações de precisão quando aplicado a sistemas de termossifão. Isso ocorre porque em sistemas forçados a taxa de fluxo da água no coletor solar é fixa e porque o fluido armazenado no reservatório está em uma condição de mistura completa. A fim de corrigirem-se tais limitações, Malkin (1985) desenvolveu o método Carta-F modificado para sistemas com circulação natural. Segundo Malkin (1985), o uso do método Carta-F original subestima a fração solar de sistemas termossifão por desconsiderar a estratificação do fluido no reservatório térmico. Como se pretende comparar os resultados desta pesquisa com a NBR 15569 (ABNT, 2008) e o RTQ-R (BRASIL, 2010b), optou-se pelo método Carta-F original, mesmo não sendo o mais indicado neste caso.

Os parâmetros adotados no dimensionamento do sistema de aquecimento solar de água da residência são apresentados a seguir:

(a) aquecedor solar destinado a atender demanda de água para banho;

(b) residência com quatro moradores;

(c) um banho diário por pessoa;

(d) tempo de banho de 10 minutos;

(e) temperatura de uso da água para banho de 40 ${ }^{\circ} \mathrm{C}$;

(f) temperatura de armazenamento no reservatório térmico de $50{ }^{\circ} \mathrm{C}$;

(g) coletor solar plano com dutos de cobre e cobertura de vidro, área útil por placa de $1,00 \mathrm{~m}^{2}$, fator de eficiência óptica 0,779 , coeficiente global de perdas de 6,795 W/( $\left.\mathrm{m}^{2} . \mathrm{K}\right)$, Ence A, Selo Procel. Posicionamento dos coletores solares: voltados para o norte geográfico com inclinação igual à latitude local acrescida de $10^{\circ}$; e

(h) reservatório térmico com revestimento de aço inox e isolamento de poliuretano, volume de $200 \mathrm{~L}$ ou $300 \mathrm{~L}$, dependendo da necessidade de armazenamento, resistência elétrica de $2.500 \mathrm{~W}$, Selo Procel. Controle de acionamento da resistência elétrica: desliga quando a temperatura da água atinge $50{ }^{\circ} \mathrm{C}$ e liga quando a temperatura chega a $45^{\circ} \mathrm{C}$, com timer programado para horários próximos ao definido para banho.
No dimensionamento do sistema solar térmico da residência foi utilizada a menor área de coletores solares que atendesse a cada condição de conforto de banho e nível de eficiência energética. Como foi escolhido um modelo de coletor solar com área de $1,0 \mathrm{~m}^{2}$, foi necessário fracionar a área do coletor em subáreas de $0,10 \mathrm{~m}^{2}$ para atender-se a todos os níveis de eficiência energética - A, B, C e D. Já em relação ao reservatório térmico, foram escolhidos modelos comerciais com menor volume, que atendessem à necessidade de armazenamento de água quente.

$\mathrm{O}$ caso de referência, representado pelo uso de chuveiro elétrico, foi atendido por modelos de chuveiros comerciais com duas opções de potências ("inverno/verão"): 4.500/3.200, $5.500 / 4.800$ e 7.500/5.500 W para as vazões de 3 , 5 e $8 \mathrm{~L} / \mathrm{min}$ respectivamente. Com base nas temperaturas médias mensais de Viçosa, foi definido que a menor potência é utilizada nos meses de janeiro, fevereiro, março, abril, outubro, novembro e dezembro, enquanto a maior potência é usada em maio, junho, julho, agosto e setembro. Dessa forma, foi possível comparar o consumo de energia do chuveiro elétrico e do sistema solar com apoio elétrico durante um ciclo anual.

O sistema de aquecimento solar de água da residência foi simulado termoenergeticamente pelo programa EnergyPlus. Diferentemente do procedimento de dimensionamento, na simulação optou-se por empregar aquecedores solares com arranjos de coletores reais, ou seja, uso de menor área inteira de $1,0 \mathrm{~m}^{2}$ que atendesse ao nível $\mathrm{A}$ para cada condição de conforto de banho. O programa EnergyPlus utiliza o método Carta-F original para analisar sistemas com circulação forçado e termossifão, assim como a NBR 15569 (ABNT, 2008) e o RTQ-R (BRASIL, 2010b). Essa ferramenta computacional tem sido empregada internacionalmente para analisar o uso de energias renováveis em edifícios, incluindo energia solar térmica (FUMO; MAGO; LUCK, 2010; MARKOVIC; CVETKOVIC; MASIC, 2011).

$\mathrm{O}$ aquecedor solar foi dimensionado e simulado para as condições meteorológicas do município de Viçosa, Minas Gerais. Foi utilizado um arquivo climático do tipo TMY (Typical Meteorological Year), desenvolvido por Guimarães e Carlo (2011), com base em séries de cinco anos do Instituto Nacional de Meteorologia (Inmet).

\section{Resultados e discussão}

O dimensionamento do sistema solar térmico para atender às diferentes condições de conforto de banho e níveis de eficiência energética pela 
certificação brasileira de edifícios residenciais é apresentado na Tabela 4.

A atual metodologia de classificação do sistema de aquecimento solar de água da certificação de edifícios residenciais, de ponderação da eficiência do sistema solar e elétrico para frações solares menores que $70 \%$, impossibilita a obtenção direta do nível de eficiência energética B. Isso ocorre devido ao peso de cada sistema no cálculo do equivalente numérico ponderado, não sendo possível alcançar equivalente igual ou superior a 4,0 (limite inferior do nível B, Tabela 3). Um sistema de aquecimento solar de água somente receberá classificação nível $\mathrm{B}$ caso possua fração solar anual igual ou superior a $70 \%$ e não atenda aos pré-requisitos do nível $\mathrm{A}$, com consequente rebaixamento de nível de A para $\mathrm{B}$. Para efeito de comparação, os dimensionamentos anteriores foram refeitos considerando-se apenas o valor da fração solar e estão apresentados na Tabela 5.

Comparando as Tabelas 4 e 5, percebe-se que a determinação do nível de eficiência energética exclusivamente pela fração solar promove o aumento em um nível na classificação do sistema de aquecimento de água, ou seja, C para B, e D para C. Entretanto, o cálculo da eficiência energética adotado atualmente pelo RTQ-R, promovendo a redução direta de nível $\mathrm{A}$ para $\mathrm{C}$, para sistemas com frações solares menores que $70 \%$, incentiva o dimensionamento de sistemas com maior aproveitamento de radiação solar.

O dimensionamento do aquecedor solar pela metodologia apresentada na NBR 15569 (ABNT, 2008) para as três condições de conforto de banho é apresentado na Tabela 6. Observa-se que o dimensionamento encontrado pelo uso da norma exige uma área de coletor solar maior que a mínima necessária para atingir o limite do nível $\mathrm{A}$ (Tabela 4), com consequentes frações solares superiores a 70\%. O método de dimensionamento apresentado na NBR 15569 (ABNT, 2008) é baseado em uma fração solar anual teórica de $70 \%$, todavia há alguns parâmetros de dimensionamento, definidos pelo usuário do método, que podem fazer com que a fração solar do sistema diferencie-se desse valor teórico. Entre eles podem ser citados o volume do reservatório térmico e o fator de correção da instalação em relação à condição ideal (coletores solares orientados para o norte geográfico e com inclinação igual à latitude local acrescida de $10^{\circ}$ ). Quanto maior o volume de armazenamento em relação ao volume mínimo necessário, maior será a fração solar, e quanto maior o fator de correção de instalação, menor a fração solar. Neste trabalho, como foram empregados modelos de reservatórios térmicos comerciais, o volume de armazenamento foi ligeiramente superior ao mínimo teórico necessário. Além disso, foi considerada a condição de instalação ideal do sistema de aquecimento solar de água. Tais considerações fizeram com que os valores de fração solar anual dos sistemas dimensionados pela norma fossem moderadamente superiores a $70 \%$.

Dessa forma, desde que os profissionais da área de aquecimento solar de água atendam às recomendações apresentados na NBR 15569 (ABNT, 2008), não é necessário adequações no dimensionamento para que seja atingido o nível máximo de eficiência para o sistema de aquecimento pela certificação brasileira de edifícios residenciais. Porém, devem ser observados os pré-requisitos apresentados no RTQ-R (BRASIL, 2010b), como coletores solares com boa classificação pelo PBE e reservatórios térmicos com Selo Procel, para que o bom nível de eficiência energética obtido pelo uso de altas frações solares seja mantido na classificação final do sistema de aquecimento de água.

Tabela 4 - Dimensionamento do sistema solar para diferentes condições de conforto de banho e níveis de eficiência energética, considerando a ponderação entre fração solar e elétrica (metodologia RTQ-R)

\begin{tabular}{c|c|c|c}
\hline Eficiência/Conforto & Reduzido & Regular & Bom \\
\hline \multirow{2}{*}{ Nível A } & CS $1,0 \mathrm{~m}^{2}$ & CS $1,9 \mathrm{~m}^{2}$ & CS $3,0 \mathrm{~m}^{2}$ \\
& RT 200 L & RT 200 L & RT 300 L \\
\hline \multirow{2}{*}{ Nível B } & - & - & - \\
& & & CS $0,9 \mathrm{~m}^{2}$ \\
\multirow{2}{*}{ Nível C } & CS $1,5 \mathrm{~m}^{2}$ & CS $2,3 \mathrm{~m}^{2}$ \\
& RT $200 \mathrm{~L}$ & RT $200 \mathrm{~L}$ & RT $300 \mathrm{~L}$ \\
\hline \multirow{2}{*}{ Nível D } & CS $0,7 \mathrm{~m}^{2}$ & CS $1,1 \mathrm{~m}^{2}$ & CS $1,8 \mathrm{~m}^{2}$ \\
& RT $200 \mathrm{~L}$ & RT $200 \mathrm{~L}$ & RT $300 \mathrm{~L}$ \\
\hline
\end{tabular}

Nota: CS área de coletor solar e RT volume do reservatório térmico. 
Tabela 5 - Dimensionamento do sistema solar para diferentes condições de conforto de banho e níveis de eficiência energética considerando-se apenas a fração solar

\begin{tabular}{c|c|c|c}
\hline Eficiência/Conforto & Reduzido & Regular & Bom \\
\hline \multirow{2}{*}{ Nível A } & CS $1,0 \mathrm{~m}^{2}$ & CS $1,9 \mathrm{~m}^{2}$ & CS $3 \mathrm{~m}^{2}$ \\
& RT $200 \mathrm{~L}$ & RT $200 \mathrm{~L}$ & RT $300 \mathrm{~L}$ \\
\hline \multirow{2}{*}{ Nível B } & CS $0,9 \mathrm{~m}^{2}$ & CS $1,5 \mathrm{~m}^{2}$ & CS $2,3 \mathrm{~m}^{2}$ \\
& RT $200 \mathrm{~L}$ & RT $200 \mathrm{~L}$ & RT $300 \mathrm{~L}$ \\
\hline \multirow{2}{*}{ Nível C } & CS $0,7 \mathrm{~m}^{2}$ & CS $1,1 \mathrm{~m}^{2}$ & CS $1,8 \mathrm{~m}^{2}$ \\
& RT $200 \mathrm{~L}$ & RT $200 \mathrm{~L}$ & RT $300 \mathrm{~L}$ \\
\hline \multirow{2}{*}{ Nível D } & CS $0,6 \mathrm{~m}^{2}$ & CS $1,0 \mathrm{~m}^{2}$ & CS $1,7 \mathrm{~m}^{2}$ \\
& RT $200 \mathrm{~L}$ & RT $200 \mathrm{~L}$ & RT $300 \mathrm{~L}$ \\
\hline
\end{tabular}

Nota: CS é a área de coletor solar e RT é o volume do reservatório térmico.

Tabela 6 - Dimensionamento do aquecedor solar conforme metodologia apresentada na NBR 15569 para as três condições de conforto de banho

\begin{tabular}{|c|c|c|}
\hline Conforto de banho & Dimensionamento NBR 15569 & Fração solar anual (\%) \\
\hline Reduzido & $\begin{array}{l}\text { CS } 1,7 \mathrm{~m}^{2} \\
\text { RT } 200 \mathrm{~L}\end{array}$ & 79,6 \\
\hline Regular & $\begin{array}{l}\text { CS } 2,8 \mathrm{~m}^{2} \\
\text { RT } 200 \mathrm{~L}\end{array}$ & 75,6 \\
\hline Bom & $\begin{array}{l}\text { CS } 4,4 \mathrm{~m}^{2} \\
\text { RT 300L }\end{array}$ & 75,7 \\
\hline
\end{tabular}

Nota: CS é a área de coletor solar e RT é o volume do reservatório térmico.

Deve ser ressaltado que a fração solar dos sistemas apresentados neste artigo foi calculada pelo método Carta-F original, atualmente empregado pelo RTQ-R (BRASIL, 2010b) e pela NBR 15669 (ABNT, 2008). Caso fosse utilizado o método Carta-F modificado, seriam obtidas, possivelmente, maiores frações solares, ou, ainda, seria necessária uma menor área de coletores solares para atender a cada nível de eficiência energética. Portanto, é necessária uma adequação do RTQ-R (BRASIL, 2010b) e da NBR 15669 (ABNT, 2008) quanto ao método de avaliação de aquecedores solares de água, os quais utilizam o método Carta-F para sistemas forçados $\mathrm{e}$ termossifão, sendo o último geralmente utilizado para aplicações residenciais no Brasil.

Uma observação importante sobre os dimensionamentos apresentados neste trabalho refere-se ao volume do reservatório térmico. Para o caso de conforto de banho reduzido, seria necessário um armazenamento mínimo de $80 \mathrm{~L}$ a $50{ }^{\circ} \mathrm{C}$ para atender à demanda de $120 \mathrm{~L} /$ dia a 40 ${ }^{\circ} \mathrm{C}$. Portanto, um reservatório térmico de $100 \mathrm{~L}$ atenderia aos dimensionamentos referentes a essa condição de conforto de banho. Porém, não existem reservatórios de $100 \mathrm{~L}$ no mercado brasileiro que possuam Selo Procel (pré-requisito do sistema de aquecimento solar de água para a obtenção de nível A). Por esse motivo optou-se por reservatórios de $200 \mathrm{~L}$ nos dimensionamentos referentes à condição de conforto reduzido. Todavia, recomenda-se que para tal condição de conforto de banho sejam utilizados reservatórios térmicos com capacidade de $100 \mathrm{~L}$, pois o uso de reservatórios com volume muito superior à demanda diária de água quente aumentam o consumo de energia elétrica auxiliar do sistema solar, devido à necessidade de manter aquecido um volume de água que não será consumido. Tal situação evidencia a necessidade de adaptação do mercado nacional de aquecimento solar de água para que a etiquetagem de edifícios possa ser aplicada com êxito no Brasil.

A seguir são apresentados e discutidos os resultados obtidos na simulação termoenergética do sistema de aquecimento solar de água da residência. Os dimensionamentos e os parâmetros avaliados nos sistemas classificados como nível A para as condições de conforto de banho reduzido, regular e bom são apresentados na Tabela 7.

A incidência de radiação sobre a área de coletores solares sofreu acréscimo linear com a melhoria da condição de conforto de banho, devido ao acréscimo de uma placa a cada aumento de nível de conforto. O valor máximo de $940,2 \mathrm{~W} / \mathrm{m}^{2}$ foi registrado no dia $26 / 10$, às $13 \mathrm{~h} 00 \mathrm{~min}$, e o valor mínimo para o mesmo horário foi verificado no dia $31 / 07$, igual a $89,30 \mathrm{~W} / \mathrm{m}^{2}$. Portanto, a magnitude da incidência solar sobre a área de coletores sofreu variação em até dez vezes para um mesmo horário no decorrer do ano. Essa grande variação de incidência pode ser explicada, além das típicas diferenças de radiação solar recebidas no período de verão e inverno, pela possível presença de nebulosidade no dia 31/07. 
Tabela 7 - Variáveis obtidas na simulação do sistema solar pelo EnergyPlus para diferentes condições de conforto de banho

\begin{tabular}{|c|c|c|c|}
\hline Variável/Conforto & Reduzido & Regular & Bom \\
\hline Área de coletores solares $\left(\mathrm{m}^{2}\right)$ & 1,0 & 2,0 & $\overline{3,0}$ \\
\hline Volume do reservatório térmico (L) & 200,0 & 200,0 & 300,0 \\
\hline $\begin{array}{l}\text { Incidência de radiação sobre a superfície dos coletores solares } \\
(\mathrm{kWh} / \mathrm{ano})\end{array}$ & $1.353,5$ & $2.707,0$ & $4.060,5$ \\
\hline Energia líquida transferida aos coletores solares (kWh/ano) & 811,9 & $1.355,9$ & $2.150,6$ \\
\hline Energia líquida armazenada no reservatório térmico (kWh/ano) & 630,3 & $1.079,8$ & $1.715,6$ \\
\hline Energia elétrica auxiliar ao sistema solar térmico (kWh/ano) & 225,9 & 345,5 & 583,5 \\
\hline $\begin{array}{l}\text { Temperatura média da água nos coletores solares }\left({ }^{\circ} \mathrm{C}\right) \text {, período de } \\
\text { incidência solar }\end{array}$ & 41,5 & 41,2 & 40,8 \\
\hline Temperatura média da água no reservatório $\left({ }^{\circ} \mathrm{C}\right)$, período integral & 49,3 & 49,1 & 48,9 \\
\hline
\end{tabular}

A energia líquida transferida aos coletores solares é representada pela incidência solar sobre a superfície dos coletores, subtraídas as perdas térmicas ocorridas nesse processo. A área total de coletores referente às condições de conforto de banho reduzido, regular e bom apresentaram perdas térmicas de $541,6 \mathrm{kWh} / \mathrm{ano}, 1.351,1$ $\mathrm{kWh} /$ ano e $1.909,9 \mathrm{kWh} /$ ano (diferença entre os valores das linhas 3 e 4 da Tabela 7) respectivamente. A razão entre a energia líquida transferida e a incidente solar é conhecida como eficiência térmica do coletor. O modelo de coletor solar simulado apresentou eficiência térmica média de $54,4 \%$, considerando-se as três condições de conforto de banho. Segundo a classificação de eficiência energética do PBE, esse modelo de coletor possui eficiência térmica de 59,8\%. A diferença entre $\mathrm{o}$ valor médio obtido nas simulações e o calculado pelo PBE pode ser devido, entre outros fatores, às condições climáticas e às vazões de teste empregadas em cada análise. A eficiência energética do coletor é um dos parâmetros mais importantes para determinar o desempenho de um aquecedor solar, influenciando diretamente no cálculo da fração solar.

A energia líquida armazenada no reservatório térmico refere-se à energia prontamente disponível para aquecimento, ou seja, desconsiderado as perdas térmicas para o meio externo. Os reservatórios referentes às condições de conforto reduzido, regular e bom apresentaram perdas térmicas de 181,6 kWh/ano, 276,1 kWh/ano e 435 $\mathrm{kWh} /$ ano (diferença entre os valores das linhas $4 \mathrm{e}$ 5 da Tabela 7) respectivamente. Comparando as perdas térmicas com o consumo de energia elétrica auxiliar (valores da linha 8 da Tabela 7), percebese que as perdas no reservatório equivalem a aproximadamente $70 \%$ do consumo da energia auxiliar. Portanto, como não é possível impedir que parte da energia gerada pelo aquecedor solar seja perdida por meio de trocas térmicas para o meio externo, deve-se optar por reservatórios revestidos por materiais de baixa condutividade térmica. Apesar de as perdas térmicas no reservatório parecerem elevadas quando comparadas ao consumo de energia auxiliar, média de $0,11 \mathrm{kWh} /$ litro/mês, estão de acordo com os valores calculados pelo PBE para os modelos de reservatórios simulados, média de 0,18 $\mathrm{kWh} / \mathrm{litro} / \mathrm{mês}$.

A temperatura média da água nos coletores solares, calculada para o período de incidência solar, foi aproximadamente igual para os sistemas dimensionados para atender às condições de conforto reduzido, regular e bom, com diferença abaixo de um grau Celsius $\left(40{ }^{\circ} \mathrm{C}\right.$ a $\left.41^{\circ} \mathrm{C}\right)$. Foram verificadas temperaturas em torno de $60{ }^{\circ} \mathrm{C}$ nas horas de máxima insolação, e temperaturas de aproximadamente $30{ }^{\circ} \mathrm{C}$ nas horas de mínima insolação, para as três condições de conforto de banho. A temperatura média da água no reservatório térmico, calculada para período integral, também foi aproximadamente igual para as três condições de conforto de banho, com diferença abaixo de um grau Celsius $\left(48{ }^{\circ} \mathrm{C}\right.$ a $49{ }^{\circ} \mathrm{C}$ ). Portanto, a temperatura média da água no reservatório térmico está acima da temperatura definida para acionamento da resistência elétrica $\left(45{ }^{\circ} \mathrm{C}\right)$, evitando-se o consumo excessivo de energia auxiliar.

O aumento da condição de conforto de banho de reduzido a regular e de regular a bom provocou um acréscimo de aproximadamente $53 \%$ e $69 \%$ no consumo de energia da resistência elétrica respectivamente. Esse aumento diferencial de consumo é devido à elevação desigual das vazões de água trabalhadas: conforto reduzido $(3 \mathrm{~L} / \mathrm{min})$, regular $(5 \mathrm{~L} / \mathrm{min})$ e bom $(8 \mathrm{~L} / \mathrm{min})$. O aumento da condição de conforto reduzido a regular exige um aquecimento adicional de $80 \mathrm{~L} / \mathrm{dia}$, enquanto de regular a bom, de $120 \mathrm{~L} / \mathrm{dia}$. 
O fluxo de energia entre os componentes principais do aquecedor solar para a condição de conforto de banho regular é apresentado na Figura 3. Percebe-se que a maior parte da energia é perdida nos coletores solares. Já as perdas no reservatório térmico poderiam ser maiores caso a condutividade térmica do material de revestimento dele fosse maior. Como pode ser visto na Figura 3, as perdas térmicas no reservatório são maiores no período de inverno, devido à menor temperatura externa, que favorece o aumento de trocas entre a água contida no reservatório e o ar externo. Além disso, o estudo para um ciclo anual possibilitou estudar a dependência mensal do sistema de energia auxiliar, inversamente relacionada à energia armazenada no reservatório térmico.

O consumo anual de energia elétrica pelas duas opções de aquecimento de água analisadas (chuveiro elétrico e aquecedor solar com apoio elétrico) e o consumo total da residência (iluminação, eletrodomésticos e aquecimento de água) são apresentados nas Tabelas 8 e 9. Adicionalmente, é exibida nas tabelas a participação do aquecimento de água no consumo total da residência nos períodos definidos "verão" (chuveiro elétrico com uso de menor potência janeiro, fevereiro, março, abril, outubro, novembro e dezembro) e "inverno" (chuveiro elétrico com uso de maior potência - maio, junho, julho, agosto e setembro).

O consumo anual de energia elétrica para atender ao sistema de iluminação e uso de eletrodomésticos foi de $644,6 \mathrm{kWh} /$ ano e de 473,0 $\mathrm{kWh} /$ ano respectivamente. Portanto, a residência brasileira típica analisada apresenta consumo de energia elétrica anual de 1.117,6 kWh/ano, excluindo-se a energia necessária para aquecimento de água, atendida por aquecedor solar ou chuveiro elétrico.

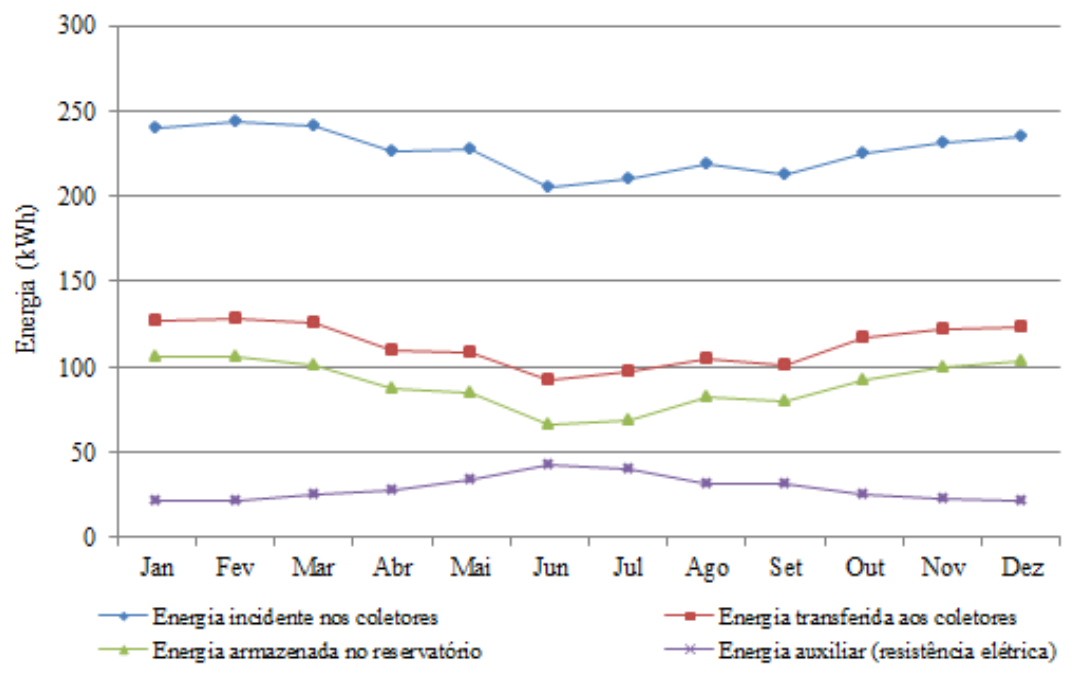

Figura 3 - Transferência de energia entre os componentes principais do aquecedor solar

Tabela 8 - Consumo de energia elétrica da residência, do chuveiro elétrico e a participação dessa opção de aquecimento de água no consumo total da residência

\begin{tabular}{l|c|c|c|c}
\hline $\begin{array}{c}\text { Conforto } \\
\text { de banho }\end{array}$ & Residência & ChWh/ano) & (kWheiro elétrico & \multicolumn{2}{c}{ Participação do chuveiro elétrico } \\
(kWh/ano) & Verão (\%) & Inverno (\%) \\
\hline Reduzido & $2.033,5$ & 915,8 & 41,1 & 49,8 \\
Regular & $2.363,2$ & 1.245 .6 & 51,1 & 54,8 \\
Bom & $2.667,7$ & $1.550,0$ & 54,5 & 62,3 \\
\hline
\end{tabular}

Tabela 9 - Consumo de energia elétrica da residência, do sistema solar com apoio elétrico e a participação dessa opção de aquecimento de água no consumo total da residência

\begin{tabular}{|c|c|c|c|c|}
\hline \multirow{2}{*}{$\begin{array}{l}\text { Conforto } \\
\text { de banho }\end{array}$} & \multirow{2}{*}{$\begin{array}{l}\text { Residência } \\
\text { (kWh/ano) }\end{array}$} & \multirow{2}{*}{$\begin{array}{c}\text { Sistema solar } \\
\text { (kWh/ano) }\end{array}$} & \multicolumn{2}{|c|}{ Participação do sistema solar } \\
\hline & & & Verão (\%) & Inverno (\%) \\
\hline Reduzido & $1.343,9$ & 225,9 & 14,3 & 20,2 \\
\hline Regular & $1.463,2$ & 345,5 & 20,3 & 27,8 \\
\hline Bom & $1.702,0$ & 583,5 & 30,1 & 39,5 \\
\hline
\end{tabular}


A participação do chuveiro elétrico no consumo total de energia elétrica da residência encontrado neste trabalho (valores da coluna 5, Tabela 8) foi consideravelmente superior à média nacional de 24\%, apontada pela Pesquisa de Posse de Equipamentos e Hábitos de Uso do Procel (ELETROBRAS, 2007). Todavia, nos últimos anos houve uma popularização de chuveiros elétricos com altas potências no país, com aumento de potências nominais típicas de $3.000 \mathrm{~W}$ para valores de 4.400 a 8.000 W (NASPOLINI; MILITÃO; RÜTHER, 2010), faixa que abrange as potências de chuveiros utilizados nesta pesquisa.

Segundo estudo realizado por Fedrigo, Ghisi e Lamberts (2009), a participação do chuveiro elétrico no setor residencial difere bastante entre as regiões geográficas, os períodos de verão e de inverno, e a faixa de consumo de energia elétrica da residência. De acordo com os mesmos autores, na região Sudeste a participação do chuveiro é de $8,3 \%$ no verão e de $35,6 \%$ no inverno. A diferença obtida entre a participação do chuveiro elétrico nesta pesquisa e os valores apontados por Fedrigo, Ghisi e Lamberts (2009) pode ser explicada, entre outros fatores, pelo elevado número de zonas bioclimáticas que abrangem a região Sudeste, causando uma heterogeneidade na demanda de água quente nessa região. Viçosa está presente na zona bioclimática 3, uma das mais frias do Brasil, o que implica maior necessidade de energia para aquecimento de água comparativamente a zonas mais quentes que estão presentes no Sudeste, como a zona bioclimática 8 (Vitória/ES e Rio de Janeiro/RJ). Para a região Sul, o estudo de Fedrigo, Ghisi e Lamberts (2009) aponta que a participação do chuveiro é de $39,4 \%$ no verão e de $43,3 \%$ no inverno, valores mais próximos aos encontrados neste trabalho.

A substituição do chuveiro elétrico pelo aquecedor solar com apoio elétrico provocou uma redução de $75 \%, 72 \%$ e $62 \%$ no consumo de energia elétrica para aquecimento de água para atender às condições de conforto reduzido, regular e bom respectivamente, um valor médio de $70 \%$. O menor consumo de energia do sistema de aquecimento de água refletiu-se no consumo energético da residência, em que a substituição do chuveiro elétrico por aquecedor solar provocou redução de aproximadamente de $34 \%$, 36\% e $38 \%$ no consumo total de energia elétrica da residência para as condições de conforto reduzido, regular e bom respectivamente, referente a uma média de $36 \%$.

Nas Figuras 4, 5 e 6 são apresentados os consumos mensais de energia elétrica pelas opções de aquecimento de água por chuveiro elétrico e sistema solar para as condições de conforto de banho reduzido, regular e bom.

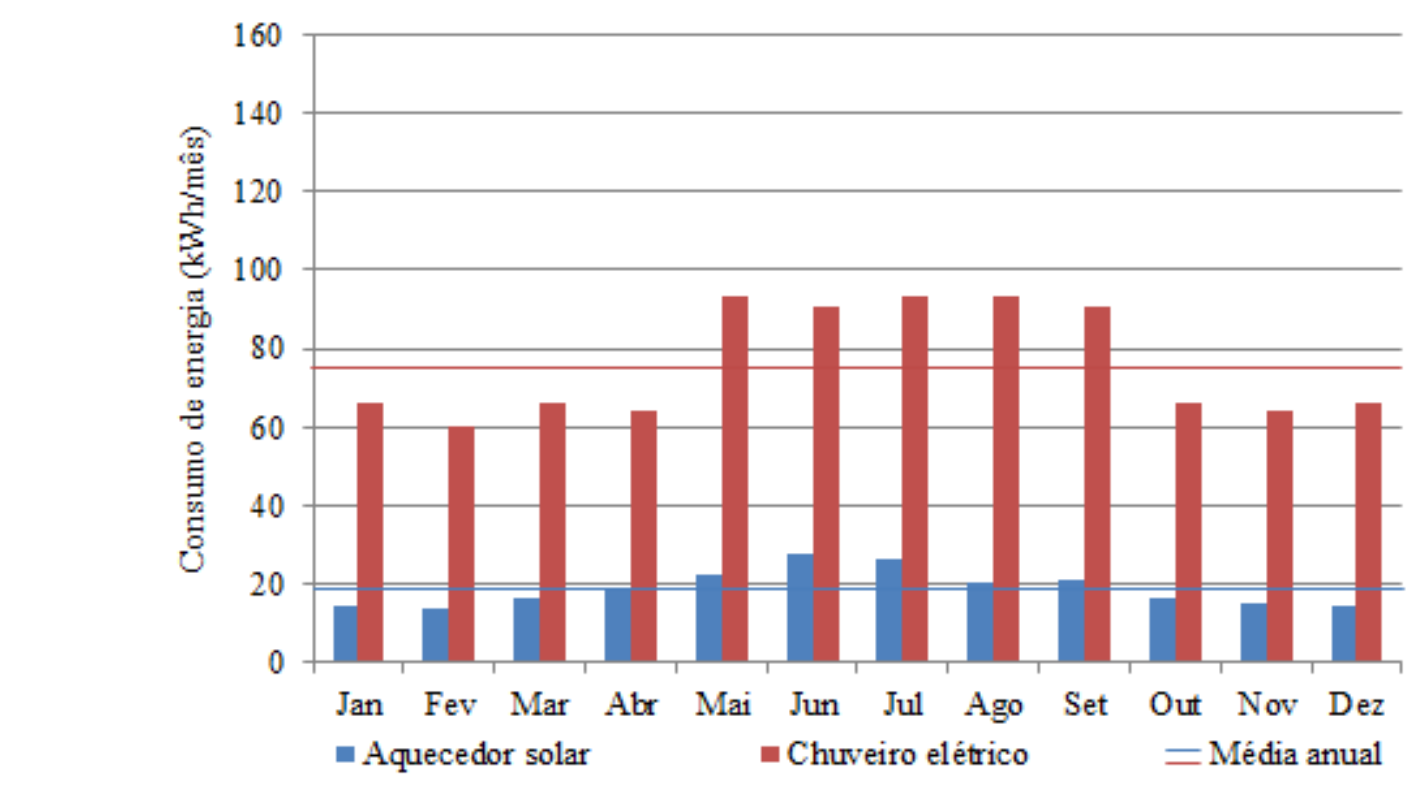

Figura 4 - Consumo de energia mensal do sistema solar com apoio elétrico e chuveiro elétrico para a condição de conforto reduzido 


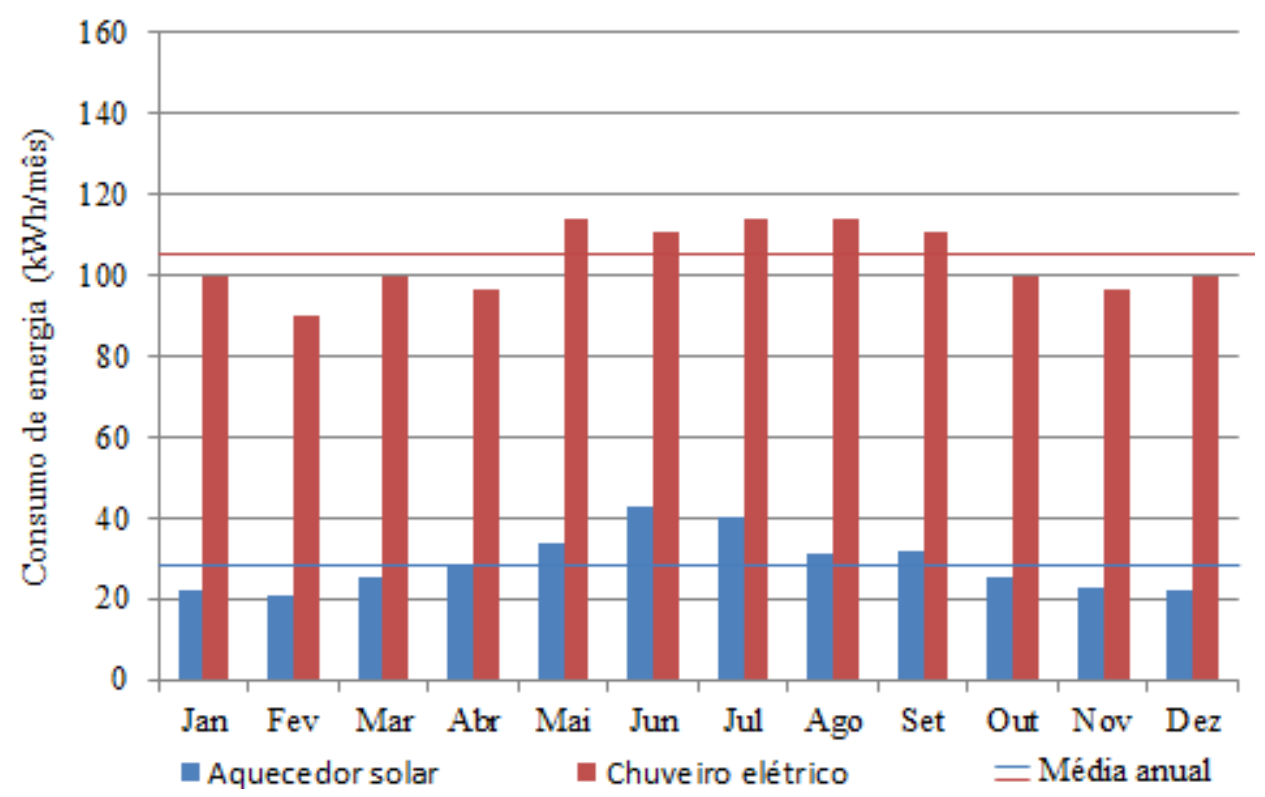

Figura 5 - Consumo de energia mensal do sistema solar com apoio elétrico e chuveiro elétrico para a condição de conforto regular

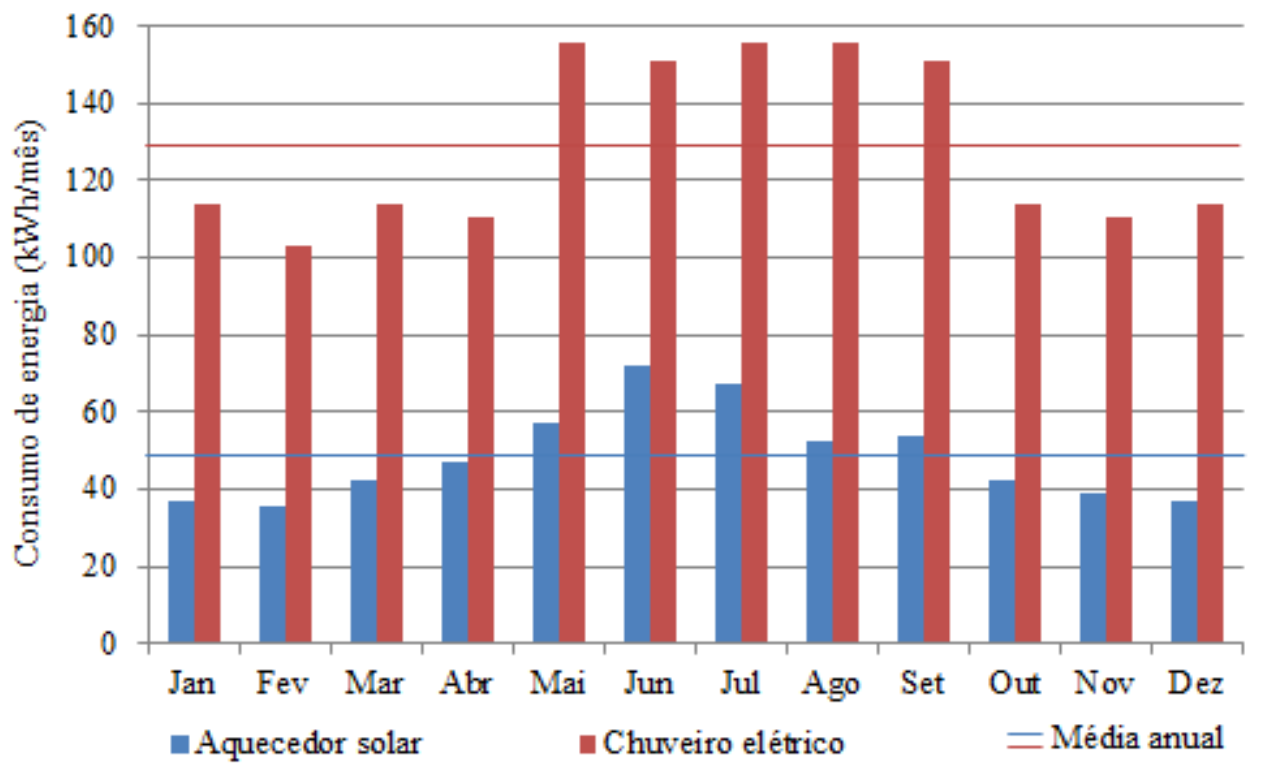

Figura 6 - Consumo de energia mensal do sistema solar com apoio elétrico e chuveiro elétrico para a condição de conforto bom

O sistema solar apresentou maior dependência de energia elétrica nos meses de maio, junho e julho, e menor dependência nos meses de janeiro, fevereiro e dezembro, para as três condições de conforto. No caso de aquecimento por chuveiro elétrico, como foram adotados equipamentos com duas opções de potências (verão/inverno), o consumo mensal de energia foi definido pela potência de uso e o número de dias do mês, ressaltando-se que foram empregados chuveiros com potências elétricas de 4.500/3.200 W, $5.500 / 4.800 \mathrm{~W}$ e $7.500 / 5.500 \mathrm{~W}$ para atender às condições de conforto reduzido, regular e bom respectivamente. A menor potência foi utilizada nos meses de janeiro, fevereiro, março, abril, outubro, novembro e dezembro, enquanto a maior potência, nos meses de maio, junho, julho, agosto e setembro.

O consumo de energia pelo uso de chuveiro elétrico foi de $76,3 \mathrm{kWh} /$ mês, $103,8 \mathrm{kWh} / \mathrm{mês}$ e $129,7 \mathrm{kWh} /$ mês para as condições de conforto reduzido, regular e bom respectivamente. Em contraste, o consumo de energia pelo emprego de sistema solar com apoio elétrico foi de 18,9 
$\mathrm{kWh} /$ mês, $28,8 \mathrm{kWh} /$ mês e $48,7 \mathrm{kWh} /$ mês para as condições de conforto reduzido, regular e bom respectivamente. Observa-se que o consumo de energia auxiliar ao aquecedor solar para atender à condição de conforto bom é menor que o consumo do chuveiro elétrico para atender à condição de conforto reduzido. Dessa forma, a substituição do chuveiro elétrico por sistema solar térmico permite a melhoria da qualidade de banho com pequeno acréscimo de consumo de energia elétrica.

\section{Conclusões}

Programas computacionais de simulação termoenergética são uma ótima opção para avaliar o uso de energias renováveis em edificações, permitindo uma análise rápida de diferentes fontes energéticas e padrões de uso. A utilização do programa EnergyPlus possibilitou uma análise comparativa entre o uso de aquecedores solares de água e chuveiros elétricos em uma residência unifamiliar para um ciclo anual.

O uso de três condições de conforto de banho e de parâmetros da certificação brasileira de edifícios residenciais permitiu avaliar a eficiência energética dos sistemas com um requisito de qualidade de banho para o usuário. A substituição do chuveiro elétrico pelo sistema solar com apoio elétrico provocou uma redução média de $70 \%$ no consumo de energia elétrica destinado a aquecimento de água doméstico e de $36 \%$ no consumo de energia elétrica total da residência.

Deve ser ressaltado que os resultados apresentados neste trabalho foram obtidos exclusivamente por meio de simulação computacional, ou seja, não houve montagem de um aquecedor solar de água com medições in loco.

A análise de sistemas com diferentes frações solares permitiu a comparação entre sistemas dimensionados pela norma brasileira de referência sobre aquecimento solar de água e a certificação de eficiência energética de edifícios residenciais. Foi verificado que, caso os profissionais da área atendam às recomendações apresentados na NBR 15569 (ABNT, 2008), não é necessário adequações no dimensionamento para que seja atingido o nível máximo de eficiência energética do sistema de aquecimento de água pelo PBE de edifícios residenciais. Porém, devem ser obedecidos os prérequisitos apresentados no RTQ-R (BRASIL, 2010b) para que o bom nível de eficiência obtido pelo uso de altas frações solares seja mantido na classificação final.

Atualmente, a certificação de eficiência energética de edifícios residenciais e a norma brasileira sobre aquecimento solar de água avaliam a eficiência de aquecedores solares pelo método Carta-F original para sistemas com circulação forçada $\mathrm{e}$ termossifão, sendo este método adequado para o primeiro tipo de sistema, e o método Carta-F modificado para o segundo. Portanto, é necessária uma adequação do RTQ-R (BRASIL, 2010b) e da NBR (ABNT, 2008) quanto ao método de avaliação de aquecedores solares de água, sendo os sistemas com circulação natural de água comumente utilizados em aplicações residenciais no Brasil.

\section{Referências}

ASSOCIAÇÃO BRASILEIRA DE NORMAS TÉCNICAS. NBR 15569: sistema de aquecimento solar de água em circuito elétrico direto: projeto e instalação. Rio de Janeiro: ABNT, 2008.

BECKMAN, W. A.; KLEIN, S. A.; DUFFIE, J. A. Solar Heating Design by the F-Chart Method. Nova York: Wiley-Interscience, 1977.

BRASIL. Ministério de Minas e Energia. Empresa de Pesquisa Energética. Balanço Energético

Nacional 2010: ano-base 2009. Relatório Final. Rio de Janeiro: EPE, 2010a.

BRASIL. Instituto Nacional de Metrologia, Normalização e Qualidade Industrial. Portaria 449, de 25 de novembro de 2010. Regulamento Técnico da Qualidade do Nível de Eficiência Energética de Edifícios Residenciais. Rio de Janeiro: INMETRO, 2010b.

CASALS, X. G. Analysis of Building Energy Regulation and Certification in Europe: their role, limitations and diferences. Energy and Buildings, v. 38, n. 5, p. 381-392, may 2006.

CRAWFORD, R. H.; TRELOAR, G. J. Net Energy Analysis of Solar and Conventional Domestic Hot Water Systems in Melbourne, Australia. Solar Energy, v. 76, n. 1/3, p. 159-163, 2004.

DEPARTAMENTO NACIONAL DE AQUECIMENTO SOLAR. Cidades sSlares.

Disponível em:

$<$ http://www.dasolabrava.org.br/informacoes/cidad es-solares/>. Acesso em: 19 abr. 2012.

ELETROBRAS - Centrais Elétricas Brasileiras S.A. Pesquisa de Posse de Equipamentos e Hábitos de Uso: ano-base 2005, classe residencial. Relatório Brasil. Rio de Janeiro: ELETROBRAS/PROCEL, 2007. 
FEDRIGO, N. S.; GHISI, E.; LAMBERTS, R. Usos Finais de Energia Elétrica no Setor Residencial Brasileiro. In: ENCONTRO NACIONAL DE CONFORTO NO AMBIENTE CONSTRUÍDO, 10., 2009, Natal. Anais... Porto Alegre: ANTAC, 2009. p. 367-376.

FOSSATI, M.; LAMBERTS, R. Eficiência Energética da Envoltória de Edifícios de Escritórios de Florianópolis: discussões sobre a aplicação do método prescritivo do RTQ-C. Ambiente Construído, Porto Alegre, v. 10, n. 2, p. 59-69, abr./jun. 2010.

FUMO, N.; MAGO, P.; LUCK, R. Methodology to Estimate Building Energy Consumption Using EnergyPlus Benchmark Models. Energy and Buildings, v. 42, n. 12, p. 2331-2337, 2010.

GUIMARÃES, I. B. B.; CARLO, J. C. Desenvolvimento do Arquivo Climático de Viçosa para Simulação Computacional de Desempenho Termo-Energético. Viçosa, MG: UFV, 2011. Relatório de pesquisa.

KALOGIROU, S. Thermal Performance, Economic and Environmental Life Cycle Analysis of Thermosiphon Solar Water Heaters. Solar Energy, v. 83, n. 1, p. 39-48, 2009.

LOMBARD, L. P.; ORTIZ, J.; POUT, C. A Review on Buildings Energy Consumption Information. Energy and Buildings, v. 40, n. 3, p. 394-398, 2008.

MALKIN, M. P. Design of Thermosyphon Solar Domestic Hot Water Systems. 125 p. Madison, 1985. Dissertação (Doutorado em Engenharia Mecânica) - Universidade de Wisconsin-Madison, Madison, WI, 1985.

MARKOVIC, D; CVETKOVIC, D.; MASIC, B. Survey of Software Tools For Energy Efficiency in a Community. Renewable and Sustainable Energy Reviews, v. 15, n. 9, p. 4897-4903, dec. 2011.

MARTINS, F. R.; PEREIRA, E. B. Enhancing Information For Solar and Wind Energy Technology Deployment in Brazil. Energy Policy, v. 39, n. 7, p. 4378-4390, 2011.
MARTINS, F. R.; PEREIRA, E. B.; ABREU, S. L. Satellite-Derived Solar Resource Maps for Brazil Under SWERA Project. Solar Energy, v. 81, n. 4, p. 517-528, 2007.

NASPOLINI, H. F.; MILITÃO, H. S. G.; RÜTHER, R. The Role and Benefits of Solar Water Heating in the Energy Demands of LowIncome Dwellings in Brazil, Energy Conversion and Management, v. 51, n. 12, p. 2835-2845, 2010.

OLIVEIRA, L. F. C. et al. Potencial de Redução do Consumo de Energia Elétrica pela Utilização de Aquecedores Solares no Estado de Goiás.

Engenharia Agrícola, v. 28, n. 3, p. 406-416, 2008.

SÃO PAULO. Câmara Municipal de São Paulo. Lei $n^{\circ} 14459$ de 03/07/2007. Diário Oficial da Cidade de São Paulo, no 121 , de 4 de julho de 2007.

SORGATO, M. J. Desempenho Térmico de Edificações Residenciais Unifamiliares Ventiladas Naturalmente. 216 f. Florianópolis, 2009. Dissertação (Mestrado em Engenharia Civil) - Escola de Engenharia, Universidade Federal de Santa Catarina, Florianópolis, 2009.

TAVARES, S. F. Metodologia Para Análise do Ciclo de Vida Energético de Edificações Residenciais Brasileiras. 225 f. Florianópolis, 2006. Tese (Doutorado em Engenharia Civil) Escola de Engenharia, Universidade Federal de Santa Catarina, Florianópolis, 2006.

THIRUGNANASAMBANDAM, M.; INIYAN, S.; GOIC, R. A Review of Solar Thermal Technologies. Renewable and Sustainable Energy Reviews, v. 14, n. 1, p. 312-322, 2010.

\section{Agradecimentos}

Os autores agradecem ao Procel Edifica/Eletrobras, ao CNPq e à Fapemig, pelo apoio para a realização desta pesquisa.

Revista Ambiente Construído

Associação Nacional de Tecnologia do Ambiente Construído

Av. Osvaldo Aranha, 99 - 3o andar, Centro

Porto Alegre - RS - Brasil CEP 90035-190

Telefone: +55 (51) 3308-4084

Fax: +55 (51) 3308-4054

www. seer. ufrgs. br/ ambienteconstruido

E-mail: ambienteconstruido@ufrgs.br 